\title{
Impact of Adenotonsillectomy on Weight Gain in Children
}

https://doi.org/10.47210/bjohns.2020.v28i2.335

Yogeesha B S, ${ }^{1}$ Savithiri Arumugam, ${ }^{1}$ Nagaraj Maradi ${ }^{1}$

Introduction

$\underline{\text { ABSTRACT }}$

'Failure to thrive' is considered to be an indication for adenotonsillectomy in children. There is contrasting evidence regarding weight gain in children following adenotonsillectomy. The objective of this study is to evaluate weight change post adenotonsillectomy.

Materials and Methods

A prospective study conducted on 45 children of age between 5 to 15 years, who underwent adenotonsillectomy in our hospital. Weight is calculated at three different period i.e. preoperative, postoperatively at 3 and 6 months and compared with standard Indian Academy of Paediatrics (IAP) weight for age.

$\underline{\text { Results }}$

Out of 45 children $62.2 \%$ were less than 10 years of age with a male preponderance of $60 \% .55 .6 \%$ had normal birth weight. Preoperatively the average weight of the participants was $25.69 \mathrm{~kg}$ when compared to IAP normal weight for age which was $29.67 \mathrm{~kg}$. Postoperatively at 6 months it was $28.19 \mathrm{~kg}$ as opposed to the expected weight of $31.88 \mathrm{~kg}$.

Conclusion

The weight gain post adeno-tonsillectomy failed to meet the expected IAP value and was below the expected value. Hence there was no significant weight change following adenotonsillectomy.

$\underline{\text { Keywords }}$

Tonsillectomy; Adenoidectomy; Weight Gain

$\mathrm{T}$ The tonsils and adenoids are the secondary lymphoid organs located in the pharynx. They are part of the inner Waldeyer's ring. Due to their typical location i.e. at the entrance of the respiratory and the alimentary tracts, they are considered as a first line of defense against the infections. Hence the recurrent and chronic infection leads to enlargement of the tonsils and adenoids.

The defence function of the tonsils and adenoids are much greater in children than in adults. Thus, adenotonsillar hypertrophy is normal in early childhood, as an index of immunological activity. They usually increase in size throughout childhood and tend to regress in adolescence. But a chronic or massive hypertrophy of adenoids and tonsils can lead to upper airway obstruction and dysphagia respectively and its consequences. ${ }^{1,2,3}$

Adenotonsillectomy (T\&A) is one of the common surgical procedures performed in the paediatric age group. Its indication has been changing from recurrent infection to hypertrophy and OSAS, due to the widespread usage of the effective oral antibiotics at the primary care level. ${ }^{4,5,6}$

In fact, failure to thrive has been an indication for T\&A, because it was noted that there was a favourable postoperative weight gain especially in underweight children, which was attributed to reduced upper airway obstruction and dysphagia. ${ }^{7,8,9}$

Recently two retrospective studies reported a significant increase in BMI percentile after adenotonsillectomy, particularly in children younger

1 - Department of Department of Otorhinolaryngology

\& Head and neck Surgery, SSIMS \& RC, Jnanashankara

campus, Davanagere

Corresponding author:

Dr Nagaraj Maradi

email: nagarajmaradi@gmail.com 
than 6 years, although no significant increase in rates of obesity was observed..$^{10,11}$ There are reports which show that only tonsillectomy had a positive influence on somatic growth postoperatively, while others found that adenoidectomy is as effective as tonsillectomy or adenotonsillectomy. ${ }^{12}$

Owing to the lack of proper conclusion from the previous studies and as there is a paucity of research in India with respect to weight gain following T\&A, we decided to conduct a study on influence of T\&A on weight in children between 5 to 15 years.

\section{Materials and Methods}

All consenting patients aged between 5 to 15 years attending outpatient department of ENT in our hospital diagnosed with Adenotonsillar Hypertrophy, during the study period of 2 years were included. Patient with concurrent diseases that may affect growth were excluded.

All the patients underwent clinical examination, pre-operative routine haematological investigations, measurement of weight, $\mathrm{X}$ ray nasopharynx or flexible Nasopharyngoscopy to look for adenoid size preoperatively. Irrespective of type of adenotonsillectomy, postoperatively. Patients were followed up after 3 months and 6 months after surgery and weight measurement was done. Children were weighted in their indoor clothing and without shoes. The measurement was plotted in Indian Academy of Pediatrician (IAP) weight for age growth chart in percentile (for boys and girls) and the IAP 50th percentile was taken as median value. The results were correlated after applying statistical tests.

The data collected was entered in Microsoft excel and analysed using IBM SPSS Version 22. Qualitative data was represented in the form of frequency and percentage. Association between qualitative variables was assessed with Fisher's exact test. Mean \& SD value was calculated for continuous variables. Inter variable comparison was done with unpaired t test, and within the group comparison were done with paired $\mathrm{t}$ test. $\mathrm{P}$ value of $<0.05$ was considered statistically significant

\section{Results}

We studied 45 children between 5 to 15 years of age. We classified them into two groups by dividing them according to their age for analytical purposes. First group was children aged 5 to 10 years and the other group had children aged 11 to 15 years. 28 belonged to the age group of 5 to 10 years and rest 17 were between 11 to 15 years i.e. $62.2 \%$ and $37.8 \%$ respectively. In our study, mean age at the time of surgery was 9.32 years. Out of 45 patients, $60 \%$ (27) were males, $40 \%$ (18) were females.

On analyzing preoperative weight distribution 7 children were in normal weight group and 38 were in below normal weight i.e. $15.6 \%$ and $84.4 \%$ respectively. Postoperative distribution of weight after 6 months showed, 6 children were in normal weight group and 39 were in below normal weight group i.e. $13 \%$ and $87 \%$ respectively. The percentage of below normal weight in preoperative $(84.4 \%)$, and postoperative $(86.7 \%)$ period were more or less same, hence there was no significant change in weight. (Fig. 1)

There was no significant change in weight between two age groups, during the preoperative and postoperative period.

Results showed that preoperatively children were below the expected weight for the age. At postoperative 3 months and 6 months following T\&A children failed to reach the expected weight for the age. (Table I)

\section{Discussion}

The present study was undertaken to determine whether adenotonsillectomy during childhood is associated with change in weight. This topic is still controversial, because many studies were showing positive results i.e. weight gain after adenotonsillectomy but some of the studies conclude that there was no weight gain following adenotonsillectomy.

Majority of the children at the time of surgery belonged to younger age group i.e. less than ten years which was comparable to other similar studies. ${ }^{11,13,14}$ On reviewing the literature for the effect of adenotonsillectomy surgery on weight gain in children, 


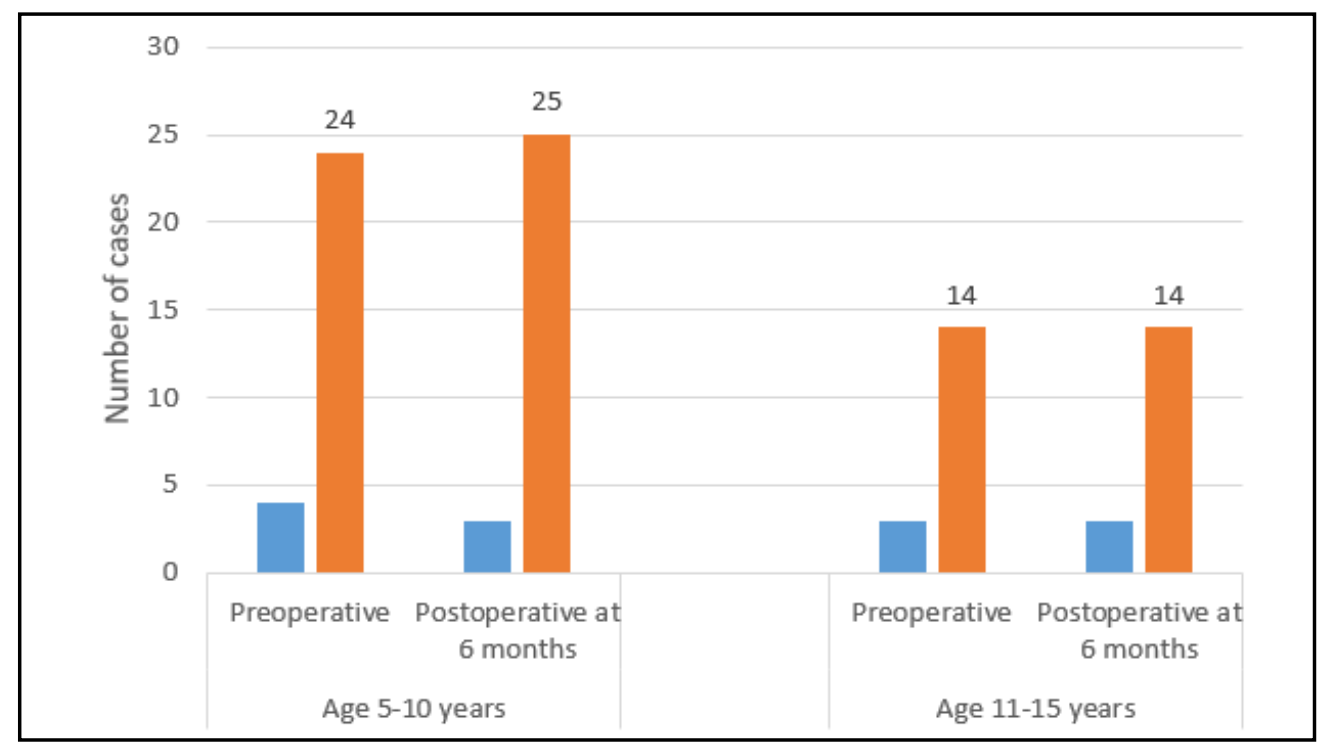

Fig. 1. Correlation of age and weight

there was contrasting evidence noted. Few studies mentioned favourable results in terms of weight gain following adenotonsillectomy. ${ }^{10,11,12}$ And in some studies the results failed to show any significant weight gain following adenotonsillectomy. ${ }^{15,16}$ In our study, there was no difference in weight changes between the two arbitrary age groups.

Also, in our study $84.4 \%$ of the children were below 50th percentile of the expected weight. This can be attributed to the rampant malnourishment in Indian paediatric population. Similar findings were noted in other studies. ${ }^{17,18}$ Czechowicz and his colleagues in their study noted that Asian children had lower weight percentiles compared to their African and European counterparts and that intervention in the form of adenotonsillectomy at a younger age group was associated with significant weight gain. ${ }^{10}$ This was especially true for children with weight percentiles in the lower range. Also, of particular importance mentioned in the above study is the point that the weight gain did not plateau until after 1 year of surgery. The immediate post-operative period is associated with decreased weight owing to the pain associated with surgery. Hence even though there is conflicting evidence regarding the role of adenotonsillectomy in children with failure to thrive, the findings of this study do not document any significant weight changes at the end of 6 months follow-up.

\section{Conclusion}

Majority of children in our study had below normal weight during preoperative period based on IAP weight for age chart median percentile. There was no significant weight gain noted after adenotonsillectomy in both normal and below normal group based on median

Table I: Mean weight of study group and IAP 50th percentile

\begin{tabular}{|c|c|c|c|}
\hline $\begin{array}{c}\text { WEIGHT WITH RESPECT TO } \\
\text { AGE (KILOGRAMS) }\end{array}$ & PREOPERATIVE & AFTER 3 MONTHS & AFTER 6 MONTHS \\
\hline According to IAP Weight & 29.67 & 30.75 & 31.88 \\
\hline Actual Weight & 25.69 & 26.81 & 28.19 \\
\hline
\end{tabular}

IAP- Indian Academy of Pediatrics 
percentile of IAP weight for age chart. Hence, we conclude that there is no impact of adenotonsillectomy on weight gain in children.

There are few drawbacks in our study. We have not taken control group of similar age and gender for comparison. Only weight of the children was taken for growth development, other parameters were not evaluated. Long term follow-up needed for definitive conclusion on effect of adenotonsillectomy on weight. The effect of adenotonsillectomy on parameters other than weight like, height, BMI, growth hormone levels, will give more valuable conclusion. The effect of adenotonsillectomy on growth can be studied more comprehensively if we have case-cohort groups who are matched for other parameters to eliminate selection bias.

\section{References}

1. Baradaranfar MH, Dodangeh F, Atar ST. Humoral and cellular immunity parameters in children before and after adenotonsillectomy. Acta Medica Iranica 2007;345-50

2. Gray LP. The T's and A's problem-assessment and reassessment. J Laryngol Otol. 1977; 91(1):11-32

3. Böck A, Popp W, Herkner KR. Tonsillectomy and the immune system: a long-term follow up comparison between tonsillectomized and non-tonsillectomized children. European archives of Oto-rhino-laryngology 1994; 251(7):423-7

4. Grundfast KM, WittichJr DJ. Adenotonsillar hypertrophy and upper airway obstruction in evolutionary perspective. The Laryngoscope 1982; 92(6):650-6

5. Lind MG, Lundell BP. Tonsillar hyperplasia in children: a cause of obstructive sleep apneas, $\mathrm{CO} 2$ retention, and retarded growth. Archives of Otolaryngology 1982;108(10):650-4

6. Deutsch ES. Tonsillectomy and adenoidectomy: changing indications. Pediatric Clinics of North America 1996; 43(6):1319-38

7. Schiffmann R, Faber J, Eidelman AI. Obstructive hypertrophic adenoids and tonsils as a cause of infantile failure to thrive: reversed by tonsillectomy and adenoidectomy. Int $\mathrm{J}$ Pediatr Otorhinolaryngol. 1985; 9(2):183-7

8. Williams III EF, Woo P, Miller R, Kellman RM. The effects of adenotonsillectomy on growth in young children. Otolaryngol Head Neck Surg. 1991 Apr;104(4):509-16

9. Hodges S, Wailoo MP. Tonsillar enlargement and failure to thrive. British Medical Journal (Clinical research ed.) 1987; 295(6597):541

10. Czechowicz JA, Chang KW. Analysis of growth curves in children after adenotonsillectomy. JAMA Otolaryngol Head Neck Surg. 2014; 140(6):491-6

11. Smith DF, Vikani AR, Benke JR, Boss EF, Ishman SL. Weight gain after adenotonsillectomy is more common in young children. Otolaryngol Head Neck Surg. 2013; 148(3):488-93

12. Vontetsianos HS, Davris SE, Christopoulos GD, DacouVoutetakis C. Improved somatic growth following adenoidectomy and tonsillectomy in young children. Possible pathogenetic mechanisms. Hormones (Athens) 2005; 4(1):4954

13. Selimoğlu E, Selimoğlu MA, Orbak Z. Does adenotonsillectomy improve growth in children with obstructive adenotonsillar hypertrophy? Journal of International Medical Research 2003; 31(2):84-7

14. Ahlqvist-Rastad J, Hultcrantz E, Melander H, Svanholm $\mathrm{H}$. Body growth in relation to tonsillar enlargement and tonsillectomy. Int J Pediatr Otorhinolaryngol. 1992; 24(1):5561

15. Roche AF. The influence of tonsillectomy on growth and caloric intake. J Pediatr. 1964; 65(3):360-7

16. Mills RP, Hibbert J. The effects of recurrent tonsillitis on growth and cervical lymphadenopathy in children. Int J Pediatr Otorhinolaryngol. 1983;6(1):77-82. doi:10.1016/s01655876(83)80105-0

17. Aydogan M, Toprak D, Hatun Ş, Yüksel A, Gokalp AS. The effect of recurrent tonsillitis and adenotonsillectomy on growth in childhood. Int J Pediatr Otorhinolaryngol. 2007; 71(11):1737-42

18. Conlon BJ, Donnelly MJ, McShane OP. Tonsillitis, tonsillectomy and weight disturbance. Int J Pediatr Otorhinolaryngol. 1997; 42(1):17-23. 